\title{
Computed Tomography, Magnetic Resonance Imaging and Pathological Correlations in a Case of Binswanger's Disease
}

\author{
M. Mascalchi, D. Inzitari, G. Dal Pozzo, N. Taverni and A.L. Abbamondi
}

\begin{abstract}
The results of 3 computed tomography (CT) examinations carried out over a 7 year period and of a post-mortem magnetic resonance (MR) study showed aspects of a white matter disease in a hypertensive patient suffering from vascular dementia. Histopathology revealed the primary cause of dementia to be a white matter degeneration sparing the $U$ fibers. Rarefaction of both the myelin sheaths and the axons was present together with severe thickening of the medullary arteries. These findings support the existence of Binswanger's disease (BD) as a distinct variety of arteriosclerotic dementia. CT and MR imaging are valuable aids for diagnosis. However, since there are many other causes of CT and MR demonstrated diffuse white matter degeneration in the elderly, a conclusive diagnosis of BD requires pathological confirmation.
\end{abstract}

RÉSUMÉ: Tomodensitométrie, imagerie par résonance magnétique nucléaire et corrélations anatomopathologiques dans un cas de maladie de Binswanger Trois tomodensitométries faites sur une période de sept ans et un examen par résonance magnétique nucléaire effectué en post-mortem ont mis en évidence des modifications compatibles avec une leuco-encéphalopathie chez un patient hypertendu atteint d'une démence vasculaire. L'histopathologie a montré que la cause primaire de la démence était une dégénérescence de la substance blanche épargnant les fibres en U. Il existait une raréfaction des gaines de myéline et des axones ainsi qu'un épaississement important des artères médullaires. Ces observations supportent la notion que la maladie de Binswanger (MB) est une variété distincte de démence artérioscléreuse. La tomodensitométrie et l'imagerie par résonance magnétique nucléaire sont des aides précieuses pour le diagnostic. Cependant, comme il existe plusieurs autres causes de dégénérescence de la substance blanche chez les sujets âgés, qui sont évidentes à la tomodensitométrie et à l'imagerie par résonance magnétique nucléaire, une confirmation anatomopathologique du diagnostique de MB est essentielle.

Can. J. Neurol.Sci. 1989; 16:214-218

The existence of Binswanger's disease (BD), or subcortical arteriosclerotic encephalopathy as a distinct form of vascular dementia has been controversial for some time. Based on an extensive review of the subject and on personal observation of 2 cases, Olszewski concluded that BD represents "a peculiar variant of cerebral arteriosclerosis in which small arteries and arterioles of the white matter and the basal ganglia are affected predominantly. Such localization of vascular changes may lead to the development of multiple areas of infarction which interrupt long subcortical fiber bundles and produce diffuse areas of demyelination with preservation of the $U$ fibers, loss of bulk of the white matter, and enlargement of the ventricles". 1

However as early as 1942 Rothschild stated that even if "...traces of BD are frequently observed in the brain of patients with arteriosclerotic psychoses...the pathologic picture scarcely merits consideration as a separate form of the disorder". ${ }^{2}$
Furthermore, cases of white matter damage considered as $\mathrm{BD}$ without arteriosclerotic changes in the penetrating vessels have been reported, ${ }^{3-5}$ as well as cases without dementia. ${ }^{5-7}$ It has recently been stated that the multiple infarcts or lacunes may be the only tissue alterations caused by the arteriosclerosis of the cerebral vessels. ${ }^{5}$

A pre-mortem diagnosis of $\mathrm{BD}$ is difficult since many of the same clinical features are observed in other forms of cerebral arteriosclerosis. ${ }^{8}$ Valuable information has come from computed tomography (CT) and magnetic resonance imaging (MRI) which show wide areas of degeneration of the cerebral white matter in pathologically proven cases of $\mathrm{BD}$.9-12

A patient with a clinical picture of vascular dementia and $C T$ evidence of diffuse white matter disease recently came to autopsy in our department. A post-mortem MR study was carried out before the histopathological examination. The latter revealed a

From the Department of Neurology University of Florence (M.M., D.I.); MR Unit, Department of Physiopathology, University of Florence (G.D.P., N.T.); Department of Neurology, Catholic University, Rome (A.L.A.)

Received April 21, 1988. Accepted in final form December 23, 1988

Reprint requests to: Mario Mascalchi MD, Department of Neurology, University of Florence, Viale Morgagni 85, 50132, Florence Italy. 
white matter and vascular disorder consistent with $\mathrm{BD}$, as the primary cause of dementia.

\section{Case Report}

The patient was first admitted to our department at age 53 following an acute onset of a confusional state and unsteadiness of gait. He was a heavy smoker and had had uncontrolled hypertension for about 15 years. He had also suffered from a myocardial infarction at age 43 . Two years later the patient began to complain of fatigue, depression, memory loss and difficulty in concentration. His first $\mathrm{CT}$ scan, done at age 51 , revealed diffuse hypodense areas in the periventricular white matter and centrum semiovale of both hemispheres. At age 52 he developed acutely a left hemiparesis and dysarthria from which he recovered incompletely within a few days. In the same year he presented with epileptic seizures; during the following hospitalization laboratory signs of diabetes and dyslipidemia were ascertained. The next year he had a series of synocopal episodes which were attributed to orthostatic hypotension.

On admission the neurological examination revealed gait ataxia, a left sided motor incoordination, a mild left hemiparesis with a Babinski sign and dysarthric speech. The patient was discharged with a diagnosis of probable infarct of the cerebellar hemisphere.

At age 54 the patient was readmitted for impairment of gait and of his mental faculties which developed progressively over about 3 weeks. The patient exhibited a small steppage wide based gait, diffuse motor slowness and limb rigidity, and was disoriented in space and time. A standardized neuropsychological battery 13 revealed a predominant deficit of both short and long term memory, slight visuo-constructional apraxia and reduction in verbal comprehension. A second CT scan confirmed the extensive hypodensity of the cerebral white matter.

The patient spent the next 3 years in a nursing home. His mental and motor dysfunction worsened progressively although there were some plateau phases. A second myocardial infarction occurred at age 57. He was then admitted to our department for a third time. He was in poor general condition, completely bed-ridden and incontinent. He was nearly mute and was not able to perform simple tasks. Flexion hypertonia of all four limbs, a generalized increase in tendon reflexes and bilateral Babinski signs were present, as well as continuous orolingual dyskinesia. A CT scan revealed a mild enlargement of the lateral ventricles and an extensive left occipital area of reduced attenuation consistent with an old cerebral infarction in addition to the cerebral white matter abnormalities noted previously (Figure 1). Three days after admission the patient had a right adversive seizure which lasted 30 minutes without generalization. Four days later he died from bronchopneumonia.

\section{Autopsy Findings}

Autopsy disclosed 2 myocardial infarctions and generalized atherosclerosis. A sclero-calcific thrombus occluded the upper part of the left vertebral artery. On gross external brain examination 2 post-infarction cysts were noted, one on the medial surface of the left occipital lobe and the other on the inferior surface of the left cerebellar hemisphere in a paramedian site.

\section{MR Examination}

Twenty-four hours after death, the entire fresh brain was removed at autopsy, placed in a plastic container and examined using a superconducting MR imager operating at $0.5 \mathrm{~T}$ (Philips Gyroscan). A spin echo (SE) multi-slice pulse sequence was used. The slice thickness was $10 \mathrm{~mm}$; the matrix $256 \times 256$ pixels. Both T1-weighted (TR $350 \mathrm{msec}$; TE $30 \mathrm{msec}$ ) and T2weighted (TR $1650 \mathrm{msec}$; TE 100 and $200 \mathrm{msec}$ ) images on the axial and sagittal planes were obtained.

MR examination revealed diffuse signal hypointensity of the periventricular white matter on T1-weighted images. In the left occipital lobe the hypointense white matter merged with a wide zone of cortical and subcortical tissue loss (Figure 2). A circumscribed area of tissue loss was also evident in the left cerebellar hemisphere. More striking were the white matter changes on T2-weighted images. A signal hyperintensity of almost the entire cerebral white matter was observed (Figure 3).

\section{Pathologic Study}

In section the cerebral white matter appeared soft and had a porous appearance. Three small $(0.2-0.3 \mathrm{~cm}$ in diameter) cavities were found, one close to the wall of the right lateral ventricle, another in the left centrum semiovale, the last deep in the pons.

The histological examination revealed a diffuse discoloration of most of the cerebral white matter (Figure 4). The U fibers and the genu of the corpus callosum were spared. A substantial correlation with the areas of CT hypodensity and modified MR signal intensity was observed. On microscopic examination the
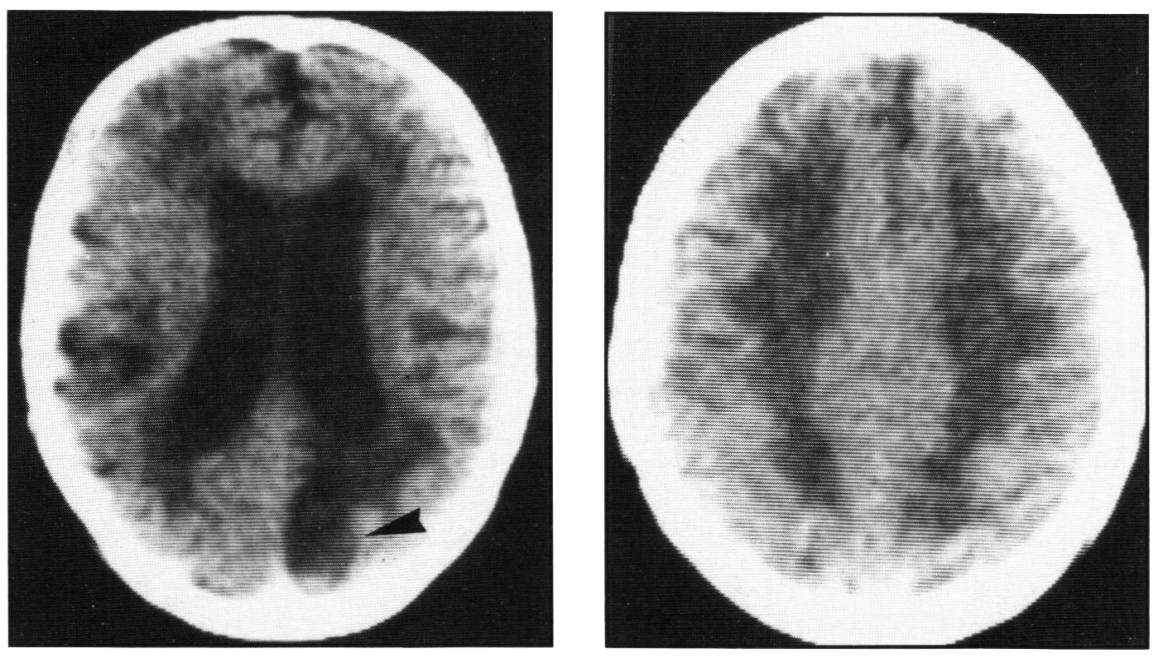

Figure I - CT scan of the patient obtained 5 days before death at the age of 57 years. Low $X$-ray attenuation of the periventricular white matter and centrum semiovale of both hemispheres, enlargement of the lateral ventricles and wide area of decreased density in the left occipital lobe (arrow'head). 
white matter alteration appeared to be due to both demyelination and axonal loss, with a moderate astroglial reaction, oligodendroglial swelling, a few macrophages and slight edema. Within the affected white matter the intensity of the process was variable with evidence of poorly defined smaller areas of more severe rarefaction which were inconstantly situated in a perivascular location. Diffuse and severe thickening of the cortical and medullary arteries with reduction of their lumen was observed. In some arteries striking hyperplasia of the intima was noted (Figure 5); in others hyalinosis was prominent. Arterioles showed similar alterations. Scarce apple birefringence Congored positive deposits were found in the wall of the meningeal cortical and medullary arteries.

The cerebral cortex showed discrete neuronal loss but only a few neurofibrillary tangles and no senile plaques. The same picture was observed symmetrically in the basal ganglia and the thalamus.

\section{Discussion}

Binswanger's description of the disease which bears his name was limited to a summary of the clinical and gross pathological findings in the cases he observed. ${ }^{14}$ The clinical picture was that of a progressive mental deterioration associated with apopleptiform attacks and epileptic seizures, leading to a decerbrate state. Pathologically the condition was characterized by cerebral white matter atrophy involving predominantly the posterior regions, hydrocephalus and severe atherosclerosis. The cerebral cortex was essentially spared.

The histopathological features of BD were outlined in subsequent cases. Alzheimer reported that: “...One can demonstrate in the white matter the presence of numerous foci producing wide areas of a secondary degeneration. In the original foci the glia is much increased and gitter cells are very numerous. However the proliferation of the supporting tissue is present in the whole of the deep white matter, with gitter cells scattered throughout...". 15 Nissl confirmed the white matter histopathological picture and emphasized thickening of the vascular walls in both the normal and affected white matter caused by concentric lamellae arranged in onion skin pattern. ${ }^{16}$
The histopathological findings in our case were similar to the ones described above. It seems unlikely in this case that the dementia was due the lacunes or the occipital infarct, which did not appear on CT until after substantial mental deterioration had already occurred. Nor were there any gray matter alterations typical of Alzheimer's disease in this case. It seems therefore reasonable to propose the diffuse white matter damage as the main cause of the dementia. The present case may thus be regarded as an example of "arteriosclerotic" dementia not sustained by lacunar or cortical infarcts but by diffuse damage of the subcortical white matter.

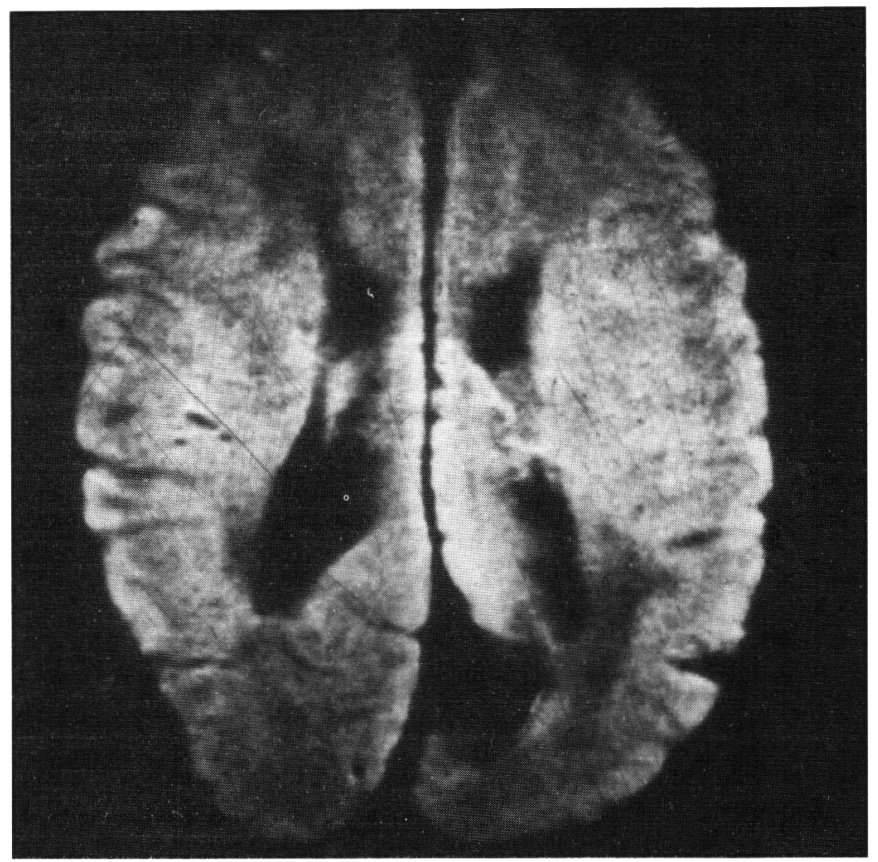

Figure 2 - Post-mortem TI weighted MR image (TR $350 \mathrm{msec}$, TE 30 msec) on the axial plane. Signal hypointensity of the periventricular. white matrer and wide zone of cortical and subcortical tissue loss in the left occipital lobe.

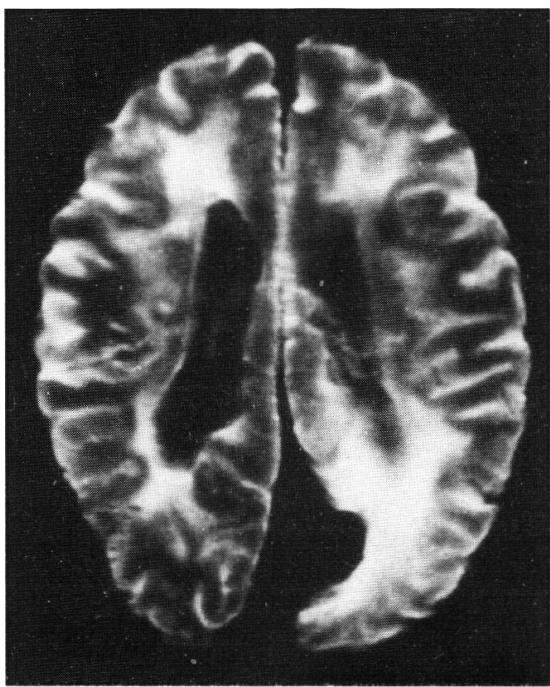

A

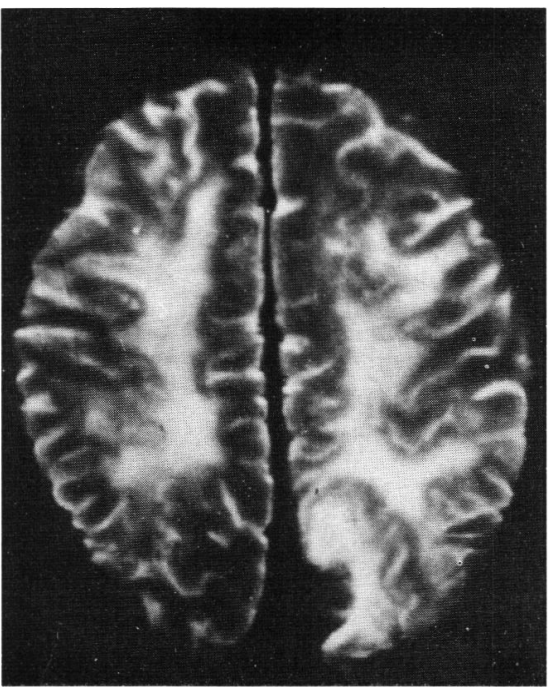

B
Figure 3 - Post-mortem 72 weighted MR images (TR $1650 \mathrm{msec}, T E 100 \mathrm{msec}$ ) on the axial plane. Signal hyperintensity of almost the entire cerebral white matter, more evident around the area of tissue loss on the medial surface of the left occipital lobe $(B)$. 


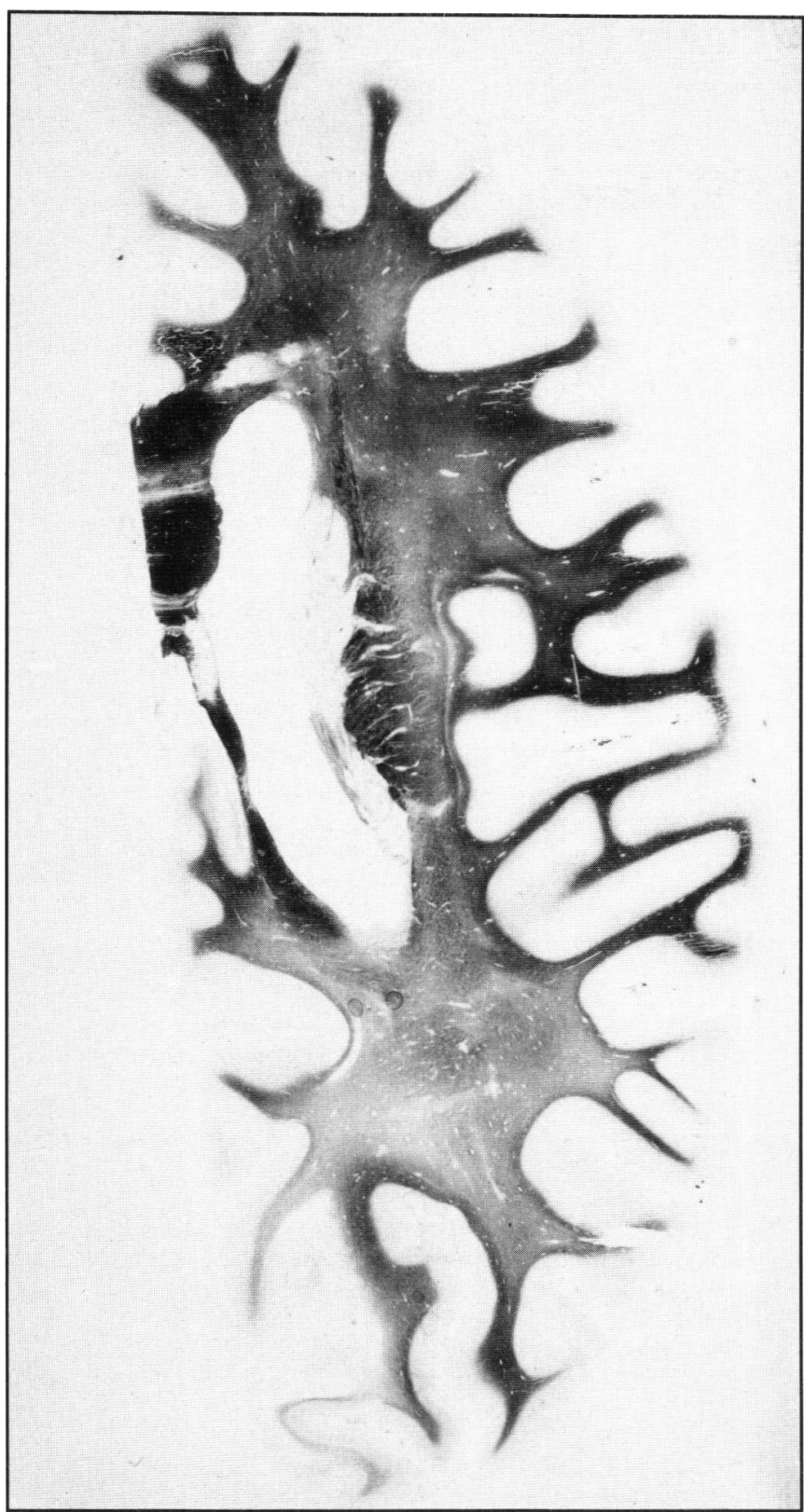

Figure 4 - Woelke stain for myelin. Transverse section of the left cerebral hemisphere, just above the occipital infarction. Diffuse discoloration of the white matter sparing the $U$ fibers and the genu of the corpus callosum.

The pathogenesis of BD is not yet defined. According to several authors the white matter alterations in BD are incomplete infarcts due to ischemia resulting from the combination of a localization of the hypertensive vascular changes in the long penetrating arteries and the scarce anastomoses connecting these vessels. 14-16 Furthermore the characteristics of the arterial border zone of the deep cerebral white matter have been outlined. 17 These, together with eventual hypotensive crises may lead to border-zone infarcts in the deep cerebral white matter, ${ }^{6}$ and actually the association of these two factors is considered one of the mechanisms responsible for the so called hypoxicischemic leukoencephalopathy, a condition implying tissue

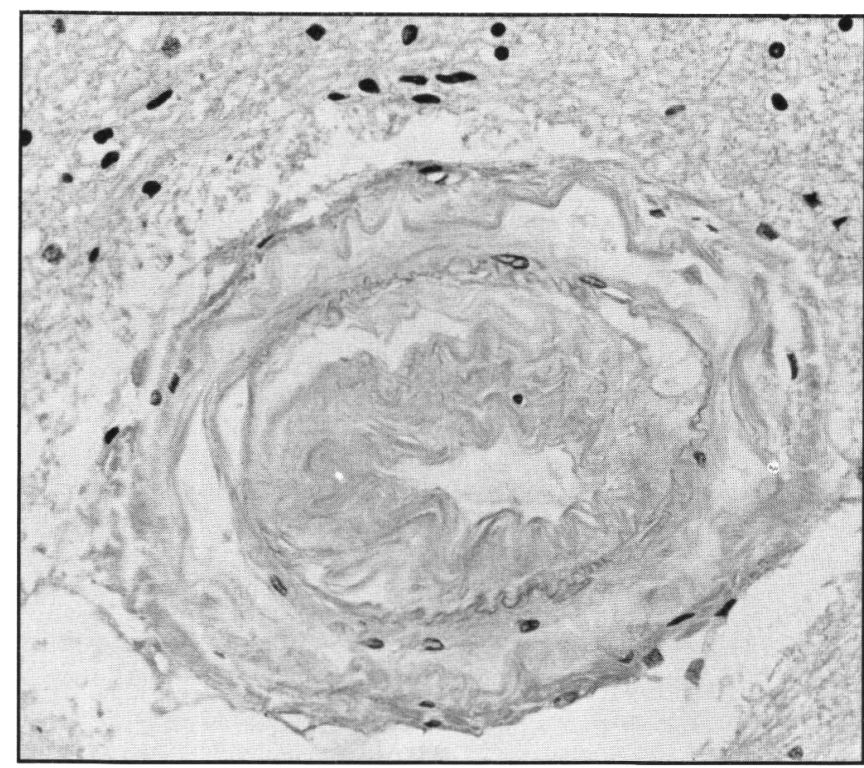

Figure 5-Hematorylin and eosin stain $(x$ 400). Marked hyperplasia of the intima of a medullary artery with severe reduction of its lumen.

changes similar to those of BD in absence of significant alterations in small arteries. ${ }^{18}$

Other authors have sustained that the white matter changes in BD might represent the late effect of chronic vasogenic edema secondary to hypertensive encephalopathy. 19

In our case the pathological study revealed severe hypertensive changes in the long penetrating arteries. Although no clear episodes of hypertensive encephalopathy occurred, the case history revealed poorly controlled long standing arterial hypertension as well as repeated episodes of hypotension. These findings lead us to suggest that a combination of all the above mechanisms, contributes to the pathogenesis of BD.

Several criteria may help diagnose BD during life. A presumed diagnosis was reached in this case on the basis of clinical and CT findings. Caplan and Schoene ${ }^{20}$ outlined the following clinical picture in pathologically proven cases of BD: age of onset between 50 and 60 , persistent arterial hypertension, acute strokes, subacute neurologic deficits; lengthy clinical course with periods of plateau; progressive dementia; prominent motor signs and pseudobulbar palsy; epileptic seizures. However none of the above can be considered specific for BD. ${ }^{8}$ Valuable aid to the diagnosis of BD has come from CT and MR which show wide areas of modification of the cerebral white matter in pathologically proved cases of BD.9-12 In our case, 3 CT scans revealed features consistent with a white matter disease. The evolution of the CT picture over a 7 year interval included the occurrence of a cortical infarct and mild dilatation of the lateral ventricles. The latter is recognized as part of the general evolution of the white matter disease. 21

Post-mortem MR examination has recently been established as an appropriate tool for the investigation of MR-pathological correlations. ${ }^{12.22-24}$ The results in our case showing wide areas of prolonged $\mathrm{T} 1$ and $\mathrm{T} 2$ relaxation times in the white matter confirm previous MR-pathological correlations in patients with BD submitted to MR ante-mortem. ${ }^{11,12}$ It should be emphasized that the extension of the MR abnormalities observed by us is 
indeed uncommon when compared to the MR picture of white matter damage often encountered in hypertensive elderly subjects suffering from cerebrovascular symptoms but without a clinical picture of vascular dementia.25 The latter is characterized by patchy or punctate areas of altered MR signal which correspond to pathological changes of arteriosclerosis, dilated perivascular spaces and vascular ectasia, referred to as etat criblé, 23.26 a picture quite dissimilar to that observed in our case, or to small cystic or non-cystic infarcts. ${ }^{24}$

CT and MR are capable of demonstrating in vivo the diffuse white matter damage of BD and should now probably be considered mandatory for differentiation of BD from other vascular dementias. However pathological pictures of diffuse white matter damage apparently similar to those of BD but with different vascular abnormalities have recently been described in demented patients with cerebral amyloid angiopathy showing CT aspects of leukoencephalopathy ${ }^{27}$ and in demented patients with otherwise typical Alzheimer's disease. ${ }^{28}$ In addition, similar findings on CT or MR examination may be produced by other white matter disorders such as multiple sclerosis, leukodystrophy, normal pressure hydrocephalus, radiation leukoencephalopathy, and hypoxic ischemic leukoencephalopathy. ${ }^{29}$ However, in most cases the clinical and pathological features are quite distinct from $\mathrm{BD}$.

At the present time the diagnosis of BD may be suggested by the clinical features but needs to be corroborated by neuroimaging techniques, and confirmed by neuropathological examination.

\section{ACKNOWLEDGEMENT}

The authors wish to thank Dr. Leila Magaro, for editorial help, and Manola Crocetti for technical assistance.

\section{REFERENCES}

1. Olszewski J. Subcortical arteriosclerotic encephalopathy. World Neurology 1965; 3: 359-374.

2. Rothschild D. Neuropathologic changes in arteriosclerotic psychoses and their psychiatric significance. Arch Neurol Psychiat 1942; 48: 417-436.

3. Orlando R, Orlando YJC. Contribution al conocimiento des las leucodefaloses tipo Binswanger. Comptes-Rendues Ve Congr Neur Intern lisbonne 1954; 4: 60-74.

4. Poppe W, Tenustedt A. Ein Beitrag Zur Encephalopathia subcorticalis Binswanger. Psychiat et Neurol 1963; 145: 27-35.

5. Huang $\mathrm{K}, \mathrm{Wu} \mathrm{L}$, Luo Y. Binswanger's disease: progressive subcortical encephalopathy or multi-infarct dementia? Can J Neurol Sci 1985; 12: 88-94.

6. De Reuck J, Crevitis L, De Coster W, et al. Pathogenesis of Binswanger chronic progressive subcortical encephalopathy. Neurology 1980; 30: 920-928.

7. Garcia-Albea E, Cabello A, Franch O. Subcortical arteriosclerotic encephalopathy (Binswanger's disease): a report of five patients. Acta Neurol Scand 1987; 75: 295-303.

8. Garcin R, Lapresle J, Lyon G. Encephalopathie souscorticale chronique de Binswanger. Etude anatomoclinique de trois observations. Rev Neurol 1973; 102: 423-440.
9. Rosenberg GA, Kornfeld M, Stovring J, et al. Subcortical arteriosclerotic encephalopathy (Binswanger): Computerized tomography. Neurology 1979; 29: 1102-1106.

10. Goto K, Ishii N, Fukasawa H. Diffuse white matter disease in the geriatric population. Radiology 1981; 141: 687-695.

11. Kinkel WR, Jacobs L, Polachini I, et al. Subcortical arteriosclerotic encephalopathy (Binswanger's disease). Arch Neurol 1985; 42: 951-959.

12. De Wytt LD, Kistler JP, Miller DC, et al. NMR-neuropathologic correlation in stroke. Stroke 1987; 18: 342-351

13. Bracco L, Amaducci L. A clinical protocol for the assessment of senile dementia of Alzheimer's type. In: Gypsen WN, Traber J, (eds.). Aging of the brain. Amsterdam: Elsiever Science Publishers, 1983: 275-282.

14. Binswanger $O$. Die Abgrenzung der allgemeinen progressiven Paralyse. Berliner Klin wochenschr 1894; 31: 1103-1105, 1137 1139, 1180-1186.

15. Alzheimer A. Die Seelenstorungen auf arteriosclerotischer Grundlage. Allgemeine Z Psychiatrie psychischger Med 1902; 59: 695-711.

16. Nissl. Zur Kasuistik der arteriosklerotischen Demenz (ein Fall von sog. "Encephalitis subcorticalis"). Ges Neurol 1920; 19:438.

17. De Reuck J. The human periventricular arterial blood supply and the anatomy of cerebral infarctions. Eur Neurol 1971; 5: 321334.

18. Ginsberg M, Hedley-Whyte ET, Richardson EP Jr. Hypoxicischemic leukoencephalopathy in man. Arch Neurol 1976; 33: 5-14

19. Feigin I, Popoff N. Neuropathological changes late in cerebral edema: the relationship of traume, hypertensive disease and Binswanger's encephalopathy. J Neuropathol Exp Neurol 1963; 22: $500-511$.

20. Caplan LR, Schoene WC. Clinical features of subcortical arteriosclerotic encephalopathy (Binswanger's disease). Neurology 1978; 28: 1206-1215.

21. Barnes DM, Enzman DR. The evaluation of white matter disease as seen on computed tomography. Radiology 1981; 138: 379383.

22. Stewart WA, Hall LD, Berry K, et al. Correlation between NMR scan and brain slice data in multiple sclerosis. Lancet 1984; ii, 412 .

23. Awad IA, Johnson PC, Spetzler RF, et al. Incidental subcortical lesions identified on Magnetic Resonance Imaging in the elderly. 11. Postmortem pathological correlations. Stroke 1986; 17: 1090-1097.

24. Braffman BH, Zimmerman RA, Trojanowski JQ, et al. Brain MR: pathologic correlation with gross and histopathology. 2 Hyperintense white matter foci in the elderly. AJNR 1988; 9: 629-636.

25. Awad IA, Spetzler RF, Hodak JA, et al. Incidental subcortical lesions identified on Magnetic Resonance Imaging in the elderly. I. Correlation with age and cerebrovascular risk factors. Stroke 1986; 17: 1084-1089.

26. Kirkpatrick JB, Hayman LA. White matter lesions in MR imaging of clinically healthy brains of elderly subjects: possible pathological basis. Radiology 1987; 162: 509-511.

27. Gray F, Dubas F, Roullet E, et al. Leukoencephalopathy in diffuse hemorrhagic cerebral amyloid angiopathy. Ann Neurol 1985; 18: 54-59.

28. Brun A, Englund E. A white matter disorder in dementia of the Alzheimer type: a pathoanatomical study. Ann Neurol 1986; 19: $253-262$

29. Valentine AR, Moseley IF, Kendall. White matter abnormality in cerebral atrophy: clinicoradiological correlations. J Neurol Neurosurg Psychiatry 1980; 43: 139-142. 